\title{
A MEDIAÇÃO DA INFORMAÇÃO ALIADA AO USO DAS TECNOLOGIAS DA INFORMAÇÃO E COMUNICAÇÃO EM UMA BIBLIOTECA ESCOLAR
}

\author{
INFORMACIÓN DE MEDIACIÓN CUMPLE CON EL USO DE \\ LA TECNOLOGÍA DE LA INFORMACIÓN Y LA \\ COMUNICACIÓN EN UNA BIBLIOTECA ESCOLAR
}

Silvana Aparecida Borsetti Gregorio Vidotti - vidotti@marilia.unesp.br

Doutora em Educação pela Universidade Estadual Paulista (UNESP/Marília). Professora de Pós-Graduação em Ciência da Informação da Universidade Estadual Paulista(UNESP/Marília).

Lucirene Andréa Catini Lanzi - lu_lanzi@hotmail.com Doutoranda em Ciência da Informação pela Universidade Estadual Paulista (UNESP/Marília). Professora de Artes do Colégio Cristo Rei, Marília.

Edberto Ferneda - edberto@terra.com Doutor em Ciência da Informação pela Universidade de São Paulo (USP). Professor do Programa de Pós-Graduação em Ciência da Informação da Universidade Estadual Paulista (UNESP/Marília).

RESUMO

Introdução: A mediação da informação promove a aproximação entre o usuário e o conteúdo de seu interesse.

Objetivos: Apresentar um recorte da dissertação "Apropriação das Tecnologias de Informação e Comunicação em bibliotecas escolares: em busca de um espaço dinâmico", onde mostraremos as diversas formas para que sejam realizadas interferências no sentido de satisfazer as necessidades informacionais em uma biblioteca escolar, baseada nas propostas do "Manifesto de um bibliotecário 2.0" de Laura Cohen, bibliotecária da Universidade de Albany, nos Estados Unidos, além de apresentar estudos feitos pelo grupo de bibliotecárias australianas: Helen Partridge, Julie Lee e Carrie Munro, que organizaram 
Silvana Aparecida Borsetti Gregorio Vidotti; Lucirene Andréa Catini Lanzi; Edberto Ferneda. A mediação da informação aliada ao uso das tecnologias da informação e comunicação em uma biblioteca escolar

um projeto para identificar as principais habilidades, conhecimentos e atributos exigidos pelo "bibliotecário 2.0", do qual participaram 81 profissionais australianos.

Metodologia: Esse estudo buscou uma pesquisa qualitativa e com análise bibliográfica das investigações apresentadas pela bibliotecária norte americana Laura Cohen e das três pesquisadoras australianas Helen Partridge, Julie Lee e Carrie Munro, para dessa forma fazermos uma comparação entre realidades e experiências, tão adversas e ao mesmo tempo semelhantes com a nossa realidade brasileira.

Resultados: Não basta utilizar as TIC na biblioteca só pela modernidade ou variedade de aplicações. É necessário ter consciência da utilidade destes ou de qualquer outro meio de interesse dos alunos para poder mostrar sua qualidade e a utilidade prática. O bibliotecário, antes de utilizar as TIC, deve fazer um levantamento profundo sobre as problemáticas com as quais esse instrumento de trabalho pode contribuir de forma relevante.

Conclusões: Eventos, atividades e estruturação física do ambiente proporcionam um claro exemplo de mediação da informação em uma biblioteca escolar, evidenciando a interferência positiva que o profissional da informação pode ter sobre os usuários e o seu comportamento informacional.

Palavras-chaves: Mediação da Informação. Tecnologias de Informação e Comunicação.

Biblioteca Escolar.

\section{INTRODUÇÃO}

O profissional de Ciência da Informação tem como principal função facilitar o acesso das pessoas às informações estejam elas nos ambientes físico ou virtual, público ou privado, etc. Ao contrário do que muitos pensam e, que em muitos casos realmente acontece, a Ciência da Informação não se caracteriza por guardar registros históricos, nem apenas preservar o conhecimento em acervos intocáveis. $O$ principal papel desta ciência é promover o acesso às informações, utilizando de diversas ferramentas e técnicas que aproximem o público das fontes de conhecimento.

Dentro desta perspectiva de atuação, na qual se busca estabelecer uma sintonia entre o receptor e o conteúdo adequado ao seu interesse, um conceito que se faz profundamente inserido é a mediação. Segundo Almeida Júnior:

Mediação da informação é toda ação de interferência realizada pelo profissional da informação, direta ou indireta; consciente ou inconsciente, singular ou plural; individual ou coletiva; que propicia a apropriação da informação que satisfaça, plena ou parcialmente, uma necessidade informacional (ALMEIDA JÚNIOR, 2008, p. 3). 
Silvana Aparecida Borsetti Gregorio Vidotti; Lucirene Andréa Catini Lanzi; Edberto Ferneda. A mediação da informação aliada ao uso das tecnologias da informação e comunicação em uma biblioteca escolar

Entende-se que a mediação pode ocorrer de diversas formas, visto que o profissional da informação, assim como profissionais de todas as áreas, transporta seu background, impressões pessoais e experiências para sua vivência no trabalho, promovendo uma mediação singular e própria.

Muitas escolas, ainda hoje, subestimam ou ignoram a importância que os recursos bibliográficos e outras fontes de informação, disponíveis na biblioteca escolar, representam para o processo de ensino aprendizagem. Por este motivo, nos casos em que a biblioteca escolar existe, é corriqueiro observar sua desativação para dar lugar a uma sala de aula ou torná-la espaço para a realização de atividades consideradas mais relevantes. Procedimentos como estes estão presentes no cotidiano escolar brasileiro e são responsáveis por inúmeros entraves na conquista pelo espaço de exercício da cidadania, especialmente das classes populares menos favorecidas economicamente. Trata-se de desrespeito aos direitos da comunidade leitora oriunda da Educação básica.

Para que a biblioteca tenha o seu lugar de destaque na instituição
escolar, faz-se necessário que os responsáveis por sua dinamização
(bibliotecários, professores e outros profissionais) desenvolvam
estratégias organizacionais menos rígidas e burocráticas, que
possibilitem o exercício de liberdade e autonomia do
leitor/pesquisador naquele espaço e facilitem o seu livre acesso à
informação. Esses profissionais não podem esquecer que o seu fazer
educativo constitui-se, mais especificamente, no desenvolvimento de
ações de mediação e de incentivo à leitura e à pesquisa junto à
comunidade escolar. (MAROTO, 2009, p.65)

Os serviços bibliotecários são atividades praticamente ausentes das escolas brasileiras. A prática cotidiana em escolas públicas ou particulares da Educação fundamental tem mostrado que a grande maioria dos professores não faz, ou não sabe fazer, uso do recurso bibliográfico e, portanto, não abre espaço para ele na escola. Percebe-se também que os professores não buscam meios para usufruir a biblioteca como um auxílio no processo de ensino aprendizagem.

Chama-se a atenção à biblioteca escolar não apenas como aquele fortuito local onde se guardam livros e materiais de consulta para a comunidade escolar, porém como a verdadeira biblioteca escolar. De modo especial, entretanto, faz-se um alerta para algo que precisa ser devidamente identificado e equacionado no decorrer desta obra. Trata-se de situações adversas no processo de ensino- 
Silvana Aparecida Borsetti Gregorio Vidotti; Lucirene Andréa Catini Lanzi; Edberto Ferneda. A mediação da informação aliada ao uso das tecnologias da informação e comunicação em uma biblioteca escolar

aprendizagem, em que não se inclui a biblioteca escolar como um dos recursos relevantes e, ainda, em que não se verifica trabalho cooperativo de mestres e bibliotecários. (MACEDO, 2005, p.24)

Precisamos estar atentos a esses fatos, e mudar esse cenário, estimulando a aproximação entre o bibliotecário e o professor para, juntos, incitarmos as mudanças que irão colocar a biblioteca no contexto escolar.

\section{REFERENCIAL TEÓRICO}

Ao tratar de mediação pensamos ser indispensável abordá-la dentro do contexto educacional, já que as bibliotecas escolares têm a importante característica de estimular o aprendizado e ser um dos pilares para descobertas de novos conhecimentos, juntamente com os professores. Neste trabalho, o objetivo principal foi buscar referências e apresentar experiências que favoreçam um novo conceito de biblioteca escolar que engloba as TIC como facilitadoras no processo de ensino aprendizagem e crescimento pessoal e coletivo, sendo local de aproximação entre aluno, professor e bibliotecário, possibilitando seu papel mais ativo dentro da instituição na qual está inserida.

Também apresentaremos uma análise prática e mediadora, referente ao Manifesto de um bibliotecário 2.0 de Laura Cohen (2006), bibliotecária dos Estados Unidos, como também divulgar estudos feitos pelo grupo de bibliotecárias australianas: Helen Partridge, Julie Lee e Carrie Munro (2010), que elaboraram um projeto para identificar as principais habilidades, conhecimentos e atributos exigidos pelo "bibliotecário 2.0", do qual 81 profissionais australianos. Aproveitando esses apontamentos, apresentaremos uma comparação junto à experiência prática da pesquisadora Lucirene Catini Lanzi junto a biblioteca escolar em que desenvolveu um trabalho de dinamização.

Segundo FARIAS (2009, p.13), "a biblioteca é vista como um espaço de expressão e aprendizado, e se tiver seu potencial devidamente explorado, pode-se tornar mediadora no aprendizado, com vistas à competência informacional". A participação do bibliotecário escolar nas atividades educacionais e seu envolvimento no planejamento escolar curricular favorecem o desenvolvimento de habilidades no aluno que, por sua vez, aprende a aprender. 
Silvana Aparecida Borsetti Gregorio Vidotti; Lucirene Andréa Catini Lanzi; Edberto Ferneda. A mediação da informação aliada ao uso das tecnologias da informação e comunicação em uma biblioteca escolar

Apesar de apresentar-se, segundo inúmeros autores, como agregadora no processo de ensino tornando-o mais dinâmico, a biblioteca escolar ainda não explora ao máximo sua prática educativa.

No Brasil, embora presente com bastante frequência no discurso bibliotecário desde a década de 1960, a função educativa desse profissional não parece ter-se concretizado na prática, havendo concordância de que o bibliotecário, mesmo reconhecendo a importância deste papel, ainda se limita a atuar na promoção da leitura e no desenvolvimento do gosto de ler. O outro espaço para aação educativa do bibliotecário na escola - auxílio à pesquisa escolar - diz respeito a esse profissional, por constituir atividade em que o aluno se envolve, ou deveria envolver-se efetivamente com a busca e o uso da informação, no ambiente da biblioteca. É, portanto, a oportunidade que se oferece ao bibliotecário para exercitar prática educativa mais ampla, contribuindo para desenvolver nos alunos habilidades informacionais. Entretanto, a escassa influência do bibliotecário na aprendizagem reflete-se perceptivelmente na forma como a pesquisa escolar acontece, conforme revelado por estudos, que observaram nítida disfunção no processo. (CAMPELLO, 2010).

Percebe-se, em geral, a biblioteca escolar excluída da proposta pedagógica das instituições de ensino. O modelo atual não a entende como mais uma opção de mediação com professores e alunos, criando um desconforto do profissional da informação diante dos demais educadores.

Declarações feitas por professores do Ensino fundamental e Médio indicam mais do que a ausência de atividades coletivamente planificadas e realizadas, mas sugerem ideias preconcebidas, com evidente desconhecimento da biblioteca como elemento integrador entre o ambiente da escola e o desenvolvimento dos alunos. Vê-se que a biblioteca não é percebida pelos professores em questão como parte integrante e importante no processo educativo. Há uma divisão de atividades e responsabilidades: "[...] O trabalho realizado lá é um e o nosso é outro. (FERREIRA, 2009).

Faz-se ainda mais necessária a participação da Ciência da Informação, por meio do bibliotecário, no contexto escolar para que sejam colocados em prática meios de cativar os alunos para pesquisas e apoiar a construção do saber, especialmente considerando o perfil do estudante atual.

O aluno atual não se contenta com um aprendizado formal, ou seja alheio ao ambiente web, ele quer vibrar com descobertas imediatas e contextualizadas no 
Silvana Aparecida Borsetti Gregorio Vidotti; Lucirene Andréa Catini Lanzi; Edberto Ferneda. A mediação da informação aliada ao uso das tecnologias da informação e comunicação em uma biblioteca escolar

espaço virtual, totalmente dominado e compreendido por ele, cuja linguagem é rápida e atual.

As Tecnologias da Informação e Comunicação (TIC) proporcionaram novas maneiras de se realizar a mediação. Com as TIC o profissional da informação consegue transpor os limites físicos e alcançar os usuários mesmo que estes não estejam presentes no ambiente da biblioteca.

Para que atenda satisfatoriamente às exigências da sociedade moderna, a biblioteca escolar precisa contar com uma boa infraestrutura bibliográfica, audiovisual e principalmente tecnológica, além de espaços adequados e profissionais qualificados e, então, oferecer propostas inovadoras para o desenvolvimento do aluno, capazes de atuar como instrumentos transformadores do cotidiano da sala de aula - onde o professor, na maioria das vezes, é o único canal de informações - ampliando o campo de debates, de conflitos e de informações.

$\mathrm{Na}$ biblioteca escolar, professores, alunos e bibliotecários poderão juntos buscar o conhecimento e discutir, passo a passo, os obstáculos para se chegar a ele.

Parafraseando Paulo Freire (1995, p. 47), que disse "Fazer a história é estar presente nela e não simplesmente nela estar representado", podemos dizer que o envolvimento dos alunos no processo de conquista da biblioteca e na sua dinamização é condição sinequa non para que ela exerça um papel de destaque dentro da instituição escolar. Mesmo sabendo que a biblioteca escolar é de todos precisamos ter sempre em mente que o seu alvo principal são os alunos, visto que é em função deles que a escola existe e que o espaço da biblioteca, quando bem administrado e incentivado, poderá converte-se no centro difusor da leitura e do conhecimento, um lugar prazeroso, atraente, a "alma" da escola.

Para que os frequentadores da biblioteca escolar tenham direito à voz e à vez nas decisões e no planejamento da mesma, é preciso que o bibliotecário promova atividades que propiciem momentos e espaços de envolvimento, de crescimento e de conquista desses direitos e dessa participação. Enfim, um espaço democrático mesmo, de promoção da leitura, de discussão e de difusão e socialização de experiências. (MAROTO, 2009, p. 79) 
Silvana Aparecida Borsetti Gregorio Vidotti; Lucirene Andréa Catini Lanzi; Edberto Ferneda. A mediação da informação aliada ao uso das tecnologias da informação e comunicação em uma biblioteca escolar

Desta forma, o bibliotecário só estará exercendo efetivamente o seu papel de co educador, quando decidir abrir mão do tecnicismo excessivo que ainda predomina na maioria das bibliotecas brasileiras, escolares ou não, e assumir conjuntamente com os professores, alunos e demais interessados, a (re) construção e a transformação da biblioteca escolar num espaço de acesso crítico às informações, de dinamização e de promoção à informação.

O bibliotecário precisa estar consciente de que a dimensão do seu fazer educativo depende do espaço que ele ocupa dentro da biblioteca e do espaço que esta, por sua vez, ocupa dentro da escola.

Como ressalta Silva (2010, p. 29), "Lançando mão de esquemas organizacionais "adequados", isto é, fundamentados no bom senso e na percepção crítica da clientela, o responsável pela biblioteca não deve transformar a utilização dos serviços em uma camisa-de-força para os usuários. Nestes termos, é a biblioteca que deve se adequar aos usuários e não, como geralmente acontece, os usuários se encaixem num quadro imenso de normas.

A partir de pesquisas, observações e experiência prática, formulam-se a seguir algumas características essenciais para o profissional responsável por uma biblioteca escolar.

Nos últimos anos, houve muita discussão e debates, para apresentar o novo perfil do bibliotecário: ser um profissional engajado, dinâmico, antenado às novas linguagens da Web, apto a ser colaborativo e a trabalhar em equipe, mediar os anseios dos usuários, ser empreendedor.

Para maior esclarecimento da importância da mudança de paradigma nas funções do bibliotecário escolar, será feita uma explanação de condutas, baseada na experiência prática e mediadora, em comentários sobre o Manifesto de um bibliotecário 2.0 de Laura Cohen (2006), bibliotecária visionária da Universidade de Albany, nos Estados Unidos, além de apresentar estudos feitos pelo grupo de bibliotecárias australianas: Helen Partridge, Julie Lee e Carrie Munro (2010), que organizaram um projeto para identificar as principais habilidades, conhecimentos e atributos exigidos pelo "bibliotecário 2.0", do qual 81 profissionais australianos participaram por entrevistas, debates e discussões para diagnosticar este novo modelo de profissional. 
Silvana Aparecida Borsetti Gregorio Vidotti; Lucirene Andréa Catini Lanzi; Edberto Ferneda. A mediação da informação aliada ao uso das tecnologias da informação e comunicação em uma biblioteca escolar

Segundo Partridge, Lee e Munro (2010, p.316), "A Biblioteca 2.0 é uma mudança na interação entre os usuários e bibliotecas em uma nova cultura de participação catalisada por tecnologias da Web Social". Ainda segundo essas estudiosas, atualmente "Bibliotecas não existem apenas por causa de livros ou informação. As bibliotecas também servem para facilitar as pessoas a participarem, interagirem e criarem. A biblioteca fornece os meios para que isso aconteça". (2010, p. 316)

Não basta fazer da biblioteca um ambiente agradável, organizado e facilitador da busca informacional. A biblioteca escolar precisa estar atualizada também com os interesses de seus usuários, além de saber compartilhar e criar situações em que os usuários possam fazer uso de seu conhecimento e partilhá-lo junto a seus pares, seja de forma presencial ou por meio da web.

É importante salientar que, atualmente, o bibliotecário escolar precisa estar inserido em ambientes digitais para um maior dinamismo. O público frequentador de uma biblioteca escolar é essencialmente de "nativos digitais" e, para que eles tenham um maior interesse por este espaço, a biblioteca precisa ser ativa, dinâmica, moderna e atualizada.

No final de 2006 Laura Cohen publicou um trabalho muito citado, O Manifesto do Bibliotecário 2.0, em que ela oferece dezessete declarações para nortear a prática profissional do bibliotecário que almeja ser um profissional atualizado e inovador. O Manifesto de Cohen não incide apenas nas habilidades e no conhecimento que o bibliotecário deve ter sobre as novas tecnologias, mas também nas suas atitudes ou ethos frente ao mundo 2.0.

Com base nesse Manifesto, na vasta experiência prática e fundamentado em um diálogo entre 81 profissionais da área na Austrália, que partilham dos mesmos anseios e vivência dos profissionais brasileiros, formularemos a seguir, algumas características essenciais para o profissional responsável por uma biblioteca escolar.

Torna-se necessário também apresentar a experiência dos pesquisadores, enquanto profissionais em biblioteca escolar no Brasil, visando confrontar as experiências apresentadas como inovadoras e dinâmicas para uma biblioteca escolar 2.0. Observem no quadro 1: 
Silvana Aparecida Borsetti Gregorio Vidotti; Lucirene Andréa Catini Lanzi; Edberto Ferneda. A mediação da informação aliada ao uso das tecnologias da informação e comunicação em uma biblioteca escolar

Quadro 1 - As novas atribuições do bibliotecário 2.0 no contexto escolar

\begin{tabular}{|c|c|c|}
\hline $\begin{array}{l}\text { Manifesto de Laura } \\
\text { Cohen }\end{array}$ & Experiência dos Australianos & $\begin{array}{c}\text { Experiência profissional no Brasil em } \\
\text { Biblioteca Escolar }\end{array}$ \\
\hline $\begin{array}{l}\text { Vou reconhecer que o } \\
\text { universo da cultura da } \\
\text { informação está mudando } \\
\text { rapidamente e que as } \\
\text { bibliotecas precisam } \\
\text { responder positivamente } \\
\text { a essas mudanças para } \\
\text { fornecer recursos e } \\
\text { serviços de que os } \\
\text { usuários precisam e os } \\
\text { quais querem. }\end{array}$ & $\begin{array}{l}\text { Gostar de ler, demonstrar habilidades com leitur, } \\
\text { interpretação de texto e trabalho em grupo; ter } \\
\text { interesse em elaborar, executar, monitorar e avaliar } \\
\text { projetos de incentivo à formação de leitores, } \\
\text { "navegadores digitais" e por que não músico.; } \\
\text { elaborar, executar e avaliar projetos de incentivo à } \\
\text { informação, sejam eles de música, artes, novas } \\
\text { tecnologias, livros, etc.; realizar projetos inovadores } \\
\text { de acesso à leitura, como a contação de histórias, a } \\
\text { teatralização de obras literárias, além de estimular o } \\
\text { conhecimento por música, artes e tecnologias; } \\
\text { mostrar tendências de pesquisa e leitura, divulgar } \\
\text { os suportes tecnológicos e destacar livros e revistas } \\
\text { mais procurados; }\end{array}$ & $\begin{array}{l}\text { O público frequentador de uma bibliot } \\
\text { nativosdigitais, aqueles que além de serem r } \\
\text { Web, também são ávidos por informações } \\
\text { bibliotecário precisa estar antenado a ess } \\
\text { acabem apreciando novos conhecimento }\end{array}$ \\
\hline $\begin{array}{l}\text { Eu vou me educar sobre } \\
\text { a cultura da informação } \\
\text { dos meus usuários e } \\
\text { procurar maneiras de } \\
\text { incorporar o que eu } \\
\text { aprender em serviços da } \\
\text { biblioteca. }\end{array}$ & $\begin{array}{l}\text { Para ser um bibliotecário } 2.0 \text { os traços de } \\
\text { personalidade são mais importantes do que as } \\
\text { habilidades "O bibliotecário } 2.0 \text { deve ser um } \\
\text { entusiasta e inspirador, deve comunicar claramente } \\
\text { uma ideia e externar a sua paixão pelo exercício da } \\
\text { profissão, deve ter visão, faísca e criatividade". }\end{array}$ & $\begin{array}{l}\text { Ser criativo, atencioso, atualizado, } \\
\text { dinâmico, responsável, solícito, } \\
\text { organizado, expressivo, pontual e } \\
\text { assíduo; ter habilidade na efetivação de } \\
\text { dinâmicas de grupo e capacidade de } \\
\text { atuação com diferentes grupos e de } \\
\text { diferentes faixas etárias; dinamizar a } \\
\text { biblioteca com professores e equipe } \\
\text { pedagógica da escola; participar } \\
\text { ativamente da construção do projeto } \\
\text { político-pedagógico da Unidade Escolar e } \\
\text { do Conselho de Classe; planejar, } \\
\text { juntamente com o grupo docente, as } \\
\text { atividades curriculares e acompanhar o } \\
\text { desenvolvimento delas, colocando à } \\
\text { disposição da comunidade escolar os } \\
\text { recursos necessários; apresentar as } \\
\text { novidades da biblioteca à comunidade } \\
\text { escolar, a fim de que sejam realizadas } \\
\text { novas práticas no espaço; }\end{array}$ \\
\hline $\begin{array}{l}\text { Eu vou me educar sobre } \\
\text { a cultura da informação } \\
\text { dos meus usuários e } \\
\text { procurar maneiras de } \\
\text { incorporar o que eu } \\
\text { aprender em serviços da } \\
\text { biblioteca. }\end{array}$ & $\begin{array}{l}\text { Bibliotecários em um mundo } 2.0 \text { engajam na prática } \\
\text { reflexiva, eles têm um conhecimento de si mesmo.... } \\
\text { eles sabem suas próprias forças. Eles estão } \\
\text { dispostos a crescer com o trabalho. Esses } \\
\text { bibliotecários não só estão dispostos a estar fora de } \\
\text { sua zona de conforto, mas, na verdade, eles estão } \\
\text { confortáveis mesmo de estando fora de sua zona } \\
\text { de conforto. }\end{array}$ & $\begin{array}{l}\text { Contribuir para a utilização e integração } \\
\text { das TIC como instrumento básico de } \\
\text { trabalho e de divulgação de informações , } \\
\text { além da socialização da biblioteca com os } \\
\text { seus usuários; ter claras noções claras de } \\
\text { organização bibliográfica e arquivamento, } \\
\text { inclusive em suportes tecnológicos; } \\
\text { disseminar informação para a comunidade } \\
\text { escolar e local utilizando os ambientes } \\
\text { colaborativos web, com o objetivo de } \\
\text { facilitar o acesso à geração do } \\
\text { conhecimento (blog, site,e-mail, redes } \\
\text { sociais). }\end{array}$ \\
\hline $\begin{array}{l}\text { Não temerei os serviços } \\
\text { do Google e afins, mas } \\
\text { sim tirarei vantagem } \\
\text { desses serviços para } \\
\text { beneficiar os usuários e } \\
\text { ao mesmo tempo, } \\
\text { fornecer serviços de } \\
\text { excelência a eles. }\end{array}$ & $\begin{array}{l}\text { O bibliotecário deve solucionar as necessidades do } \\
\text { seu público, observando o seu grau de instrução, } \\
\text { inteirando-o a buscar o conhecimento onde ele } \\
\text { estiver apto para instruir-se. }\end{array}$ & $\begin{array}{c}\text { O bibliotecário não deve desprezar } \\
\text { buscadores informacionais como o Google } \\
\text { e afins, se for este o buscador em que o } \\
\text { seu público mais interage, então será este } \\
\text { o buscador com que o bibliotecário usará } \\
\text { para orientá-los a utilizar da melhor } \\
\text { maneira possível, informando-os sobre } \\
\text { todos os seus recursos. }\end{array}$ \\
\hline $\begin{array}{l}\text { Eu estarei disposto a ir } \\
\text { onde os usuários estão, } \\
\text { para praticar a minha } \\
\text { profissão. }\end{array}$ & & $\begin{array}{l}\text { A biblioteca precisa estar estruturada para } \\
\text { receber ou ir onde estejam os usuários, } \\
\text { seja numa sala de aula, ou na Webpara } \\
\text { que eles estejam sempre a par dos novos } \\
\text { acontecimentos e das novas informações. }\end{array}$ \\
\hline
\end{tabular}

Inf. Inf., Londrina, v. 19, n. 2, p. 117 - 137, maio./ago. 2014. http:www.uel.br/revistas/informacao/ 

uma biblioteca escolar

\begin{tabular}{|c|c|c|}
\hline $\begin{array}{l}\text { Vou criar sites abertos } \\
\text { que permitam aos } \\
\text { usuários juntarem-se aos } \\
\text { bibliotecários para } \\
\text { construir conteúdo e } \\
\text { melhorar sua experiência } \\
\text { de aprendizagem. E } \\
\text { prestar assistência a seus } \\
\text { pares }\end{array}$ & & $\begin{array}{l}\text { A divulgação dos novos conhecimentos, } \\
\text { informações e atualização do cotidiano da } \\
\text { biblioteca deve ser anunciada seja por de } \\
\text { um site, blog, ou redes sociais como o } \\
\text { Facebooke/ou Twitter. Com esses } \\
\text { ambientes colaborativos a biblioteca } \\
\text { poderá estar conectada ao seu público, } \\
\text { seja no período de férias (escolares) ou } \\
\text { mesmo nos finais de semana, mantendo } \\
\text { uma camaradagem . }\end{array}$ \\
\hline $\begin{array}{l}\text { Eu vou ser corajoso em } \\
\text { propor novos serviços e } \\
\text { novas formas de } \\
\text { prestação de serviços, } \\
\text { mesmo que alguns dos } \\
\text { meus colegas sejam } \\
\text { resistentes }\end{array}$ & & $\begin{array}{l}\text { Ter participado e/ou se comprometer a } \\
\text { participar e ou organizar eventos literários, } \\
\text { feiras de livros, sessões de autógrafos, } \\
\text { seminários, cursos de formação e } \\
\text { atualização em ambientes digitais, e ainda } \\
\text { estar atento aos grandes lançamentos } \\
\text { editoriais; ter facilidade em buscar } \\
\text { parceria para obtenção de recursos para a } \\
\text { biblioteca; promover programas e eventos } \\
\text { culturais; viabilizar e motivar os bate- } \\
\text { papos de autores locais e regionais, , via } \\
\text { web ou presencial, bem como pessoas } \\
\text { interessantes como de forma de estimular } \\
\text { a curiosidade dos aprendizes em relação } \\
\text { a mais descobertas. }\end{array}$ \\
\hline $\begin{array}{l}\text { Vou desfrutar da emoção } \\
\text { e diversão de uma } \\
\text { mudança positiva e vou } \\
\text { transmitir isso para os } \\
\text { colegas e usuários. }\end{array}$ & $\begin{array}{l}\text { Um dos requisitos fundamentais para ser um } \\
\text { bibliotecário } 2.0 \text { seria de envolver-se em } \\
\text { comunicação oral e em diversos formatos e mídias; } \\
\text { "o bibliotecário } 2.0 \text { deve ser bom em marketing e } \\
\text { promoção, deve ser capaz de vender suas } \\
\text { habilidades e conhecimentos", trabalhar com } \\
\text { sucesso como parte de uma equipe multidisciplinar; } \\
\text { "bibliotecário } 2.0 \text { deve ser capaz de construir } \\
\text { relacionamentos e parcerias e estabelecer redes } \\
\text { com indivíduos e grupos onde for necessário. Ele } \\
\text { precisa ser um dos jogadores da equipe e ser capaz } \\
\text { de trabalhar em colaboração com as outras } \\
\text { disciplinas". Também é necessário que tenha um } \\
\text { espírito empreendedor "eles entendem que a } \\
\text { capacidade de mudar é uma coisa vital" e estão } \\
\text { dispostos "a abrir mão dos status quo são } \\
\text { inovadores que entendem como ser empreendedor, } \\
\text { saem e procuram vantagens para a biblioteca. O } \\
\text { bibliotecário } 2.0 \text { é um líder." }\end{array}$ & $\begin{array}{l}\text { Como é gostoso partilhar os ganhos com } \\
\text { toda a equipe que auxiliou neste projeto, } \\
\text { incluir também os usuários nessas } \\
\text { conquistas e salientar que, sem eles, não } \\
\text { haveria o sucesso. }\end{array}$ \\
\hline $\begin{array}{c}\text { Eu não vou ficar na } \\
\text { defensiva sobre a minha } \\
\text { biblioteca, mas analisarei } \\
\text { claramente a sua situação } \\
\text { e farei uma avaliação } \\
\text { honesta sobre o que pode } \\
\text { ser realizado. } \\
\end{array}$ & & $\begin{array}{l}\text { Talvez esta seja a declaração de Laura } \\
\text { Cohen mais difícil de realizar. É muito } \\
\text { complexo fazer uma autoanálise do que } \\
\text { não está indo bem. Para isso é preciso um } \\
\text { trabalho em equipe, um trabalho baseado } \\
\text { no diálogo, na franqueza e no respeito. }\end{array}$ \\
\hline $\begin{array}{l}\text { Vou me tornar um } \\
\text { participante ativo no } \\
\text { movimento para a } \\
\text { divulgação da minha } \\
\text { biblioteca. }\end{array}$ & & $\begin{array}{c}\text { Divulgar as propostas dos trabalhos à } \\
\text { serem desenvolvidas na biblioteca no } \\
\text { decorrer do ano é de suma importância. } \\
\text { Esta divulgação deve ser feita aos } \\
\text { parceiros (professores, alunos, } \\
\text { coordenadores e funcionários em geral) } \\
\text { para que todos possam auxiliar no } \\
\text { sucesso das atividades e nas novas } \\
\text { conquistas. }\end{array}$ \\
\hline $\begin{array}{l}\text { Vou reconhecer que as } \\
\text { bibliotecas mudam } \\
\text { lentamente, e vou } \\
\text { trabalhar com meus } \\
\text { colegas para acelerar a } \\
\text { nossa resposta à } \\
\text { mudança. }\end{array}$ & & $\begin{array}{c}\text { Não é possível realizar uma mudança } \\
\text { estrutural sozinho, é preciso todo o } \\
\text { engajamento da equipe profissional. Caso } \\
\text { haja resistência, é preciso ouvir as partes } \\
\text { e mediar a melhor decisão, prevalecendo } \\
\text { o desejo da maioria. Às vezes é melhor } \\
\text { retroagir, e esperar uma nova } \\
\text { oportunidade. }\end{array}$ \\
\hline
\end{tabular}


Silvana Aparecida Borsetti Gregorio Vidotti; Lucirene Andréa Catini Lanzi; Edberto Ferneda. A mediação da informação aliada ao uso das tecnologias da informação e comunicação em uma biblioteca escolar

\begin{tabular}{|c|c|c|}
\hline $\begin{array}{l}\text { Eu vou ser corajoso em } \\
\text { propor novos serviços e } \\
\text { novas formas de } \\
\text { prestação de serviços, } \\
\text { mesmo que alguns dos } \\
\text { meus colegas sejam } \\
\text { resistentes. }\end{array}$ & & $\begin{array}{l}\text { Em alguns casos, vale manter uma } \\
\text { proposta que venha agregar vantagens ao } \\
\text { funcionamento da biblioteca. Desde que } \\
\text { não haja grandes conflitos na equipe. }\end{array}$ \\
\hline $\begin{array}{l}\text { Vou desfrutar da emoção } \\
\text { e diversão de uma } \\
\text { mudança positiva e vou } \\
\text { transmitir isso para os } \\
\text { colegas e usuários. }\end{array}$ & & $\begin{array}{l}\text { Após um trabalho bem sucedido é } \\
\text { importante o agradecimento toda a } \\
\text { equipe que contribuiu para a conquista. }\end{array}$ \\
\hline $\begin{array}{c}\text { Deixarei de usar as } \\
\text { práticas anteriores, caso } \\
\text { haja uma melhor maneira } \\
\text { de fazer as coisas agora, } \\
\text { mesmo que essas } \\
\text { práticas antes } \\
\text { parecessem adequadas. }\end{array}$ & & $\begin{array}{l}\text { Não ter receio de inovar. É sempre } \\
\text { benéfico experimentar o novo. }\end{array}$ \\
\hline $\begin{array}{l}\text { Tomarei uma abordagem } \\
\text { experimental para a } \\
\text { mudança e estarei } \\
\text { disposto a cometer erros. }\end{array}$ & & $\begin{array}{c}\text { Só não comete erros aquele que não } \\
\text { tenta! É salutar admitir as falhas e } \\
\text { aprender com elas. }\end{array}$ \\
\hline $\begin{array}{c}\text { Não vou esperar até que } \\
\text { algo esteja perfeito antes } \\
\text { de liberá-lo. Vou modificá- } \\
\text { lo com base no feedback } \\
\text { dos usuários. }\end{array}$ & $\begin{array}{l}\text { O bibliotecário com o perfil } 2.0 \text { sabe como liderar e } \\
\text { motivar, é um indivíduo adaptável, flexível, } \\
\text { persistente e resistente "É um acionador de partida, } \\
\text { que não tem medo e está disposto a assumir riscos } \\
\text { calculados. O bibliotecário } 2.0 \text { busca a perfeição, } \\
\text { não a excelência. Tem a mente aberta e está } \\
\text { disposto a tentar coisas novas e a aprender com as } \\
\text { suas falhas. Seu mantra é apenas faça isso". }\end{array}$ & $\begin{array}{l}\text { Para que não haja tantos desacertos, é } \\
\text { interessante que haja um bom diálogo } \\
\text { entre o bibliotecário e os usuários; o } \\
\text { primeiro propondo novas atividades e } \\
\text { recursos e o segundo dando o seu, } \\
\text { parecer sobre as novas propostas. É } \\
\text { preciso sempre ter em mente que a } \\
\text { biblioteca deve funcionar para atrair } \\
\text { novos usuários. }\end{array}$ \\
\hline
\end{tabular}

Fonte: Elaborado pela Lucirene CatiniLanzi ${ }^{1}$

\section{PROCEDIMENTOS METODOLÓGICOS}

Este estudo buscou uma pesquisa qualitativa e com análise bibliográfica das investigações apresentadas pela bibliotecária norte americana Laura Cohen e das três pesquisadoras australianas Helen Partridge, Julie Lee e CarrieMunro, para dessa forma fazermos uma comparação entre realidades e experiências, tão adversas e ao mesmo tempo semelhantes com a nossa realidade brasileira.

O bibliotecário escolar precisa estar atento a essa nova forma de cognição para, de fato, haver uma aproximação concreta e criar um vínculo forte entre as partes (bibliotecário e usuário). Ele pode aliar o espaço físico aos ambientes digitais, estimulando desta forma aqueles que não frequentam a biblioteca por falta de tempo ou mesmo vontade, buscando-os por meio da redes sociais, como também aperfeiçoando o espaço físico e buscando novos recursos virtuais para um maior aditamento:

${ }^{1}$ Quadro extraído: LANZI, Lucirene Andrea Catini. Apropriação das Tecnologias de Informação e Comunicação em Bibliotecas Escolares: em busca de um espaço dinâmico. 176 páginas. Dissertação (Mestrado em Ciência da Informação) - Faculdade de Filosofia e Ciências, Universidade Estadual Paulista, Marília. 2012.

Inf. Inf., Londrina, v. 19, n. 2, p. 117 - 137, maio./ago. 2014. 
Silvana Aparecida Borsetti Gregorio Vidotti; Lucirene Andréa Catini Lanzi; Edberto Ferneda. A mediação da informação aliada ao uso das tecnologias da informação e comunicação em uma biblioteca escolar

\begin{abstract}
Ao contrário de muitos "imigrantes digitais", os "nativos digitais" passam grande parte da vida online, sem distinguir entre o online e 0 off-line. Em vez de pensarem na sua identidade digital e em sua identidade no espaço real como coisas separadas, eles têm apenas uma identidade "São unidos por um conjunto de práticas comuns, incluindo a quantidade de tempo que passam usando tecnologias digitais, sua tendência para as multitarefas, os modos como se expressam e se relacionam um com o outro de maneiras mediadas pelas tecnologias digitais- computadores, telefones celulares, Sidekickis- são os principais mediadores das conexões humanoscom-humanos"(PALFREY, 2011, P.14)
\end{abstract}

A criatividade do bibliotecário pode conduzi-lo a desenvolver uma infinidade de atividades complementares dentro e fora do espaço físico da biblioteca escolar. Mais do que um local para empréstimos de livros e estudos silenciosos, a biblioteca escolar pode ser um ambiente dinâmico que, por meio da sua programação e recursos digitais, atraia ativamente os visitantes, sem necessitar que eles a frequentem apenas quando se deparam com uma necessidade específica.Abaixo seguem sugestões, fruto de análises e testes, para dinamizar o trabalho na biblioteca, aproveitando o interesse dos alunos por ambientes digitais:

Horas do Conto: As histórias transmitem valores morais, intelectuais, sociais, éticos. Estimulam a atenção, o censo crítico, a imaginação e a concentração. Além disso, trabalham a auto-estima de quem conta e de quem as ouve. Também incentiva a resolução de conflitos. Diante de todos estes benefícios, fica nítido que as histórias são um importante instrumento para estreitar a relação bibliotecário-aluno, especialmente quando valorizada a livre interpretação, permitindo que o leitor viaje na sua própria imaginação. Se a contação de histórias for alicerçada por ambientes digitais, por pesquisas na web para um respaldo informacional; a utilização de tablet ${ }^{4}$ para uma contação de história discernida e inovadora, certamente atrairá mais o interesse dos aprendizes.

Debates: Os debates são ótimos para desenvolver e estimular o raciocínio crítico. Essas ocasiões fazem os alunos interpretar

\footnotetext{
${ }^{2}$ Palfrey (2011, p.13 diz: "Os Imigrantes Digitais são aqueles que aprenderam tarde na vida a mandar e-mails e usar as redes sociais".

${ }^{3}$ Segundo Palfrey $(2011$, p. 7) "Os Nativos Digitais são crianças nascidas após a década de 80 e que passam grande parte do tempo conectados. Eles têm muitos amigos, tanto no espaço real quanto nos mundos virtuais,"

${ }^{4}$ Trabalho apresentado IV SECIN: LANZI, Lucirene A. C.; FERNEDA, Edberto; VIDOTTI, Silvana A. B. G.. Leitura e as TIC: a hora do conto utilizando tablet. IV SECIN - SEMINÁRIO EM CIÊNCIA DA

INFORMAÇÃO. 4. 2011. Londrina. Anais... Londrina: 2011
}

Inf. Inf., Londrina, v. 19, n. 2, p. 117 - 137, maio./ago. 2014. http:www.uel.br/revistas/informacao/ 
Silvana Aparecida Borsetti Gregorio Vidotti; Lucirene Andréa Catini Lanzi; Edberto Ferneda. A mediação da informação aliada ao uso das tecnologias da informação e comunicação em uma biblioteca escolar

situações e refletir sobre diversos aspectos para ter uma visão detalhada sobre determinado tema. Faz com que eles busquem mais informações sobre o assunto, ou queiram saber mais. Utilizar as redes sociais da biblioteca para continuar a fomentar o assunto, em chats de discussões, aproximará aqueles que não puderam participar daqueles que participaram. Além disso, os interessados sentem-se estimulados a anexar textos, vídeos ou imagens que achem curioso divulgar.

Saraus: Os Saraus constituem um excelente modo de reunir os alunos de modo descontraído, transmitindo a eles a alegria que um evento cultural unindo literatura e música pode proporcionar. Além disso, os saraus também são uma oportunidade de proporcionar integração entre alunos, coordenadores pedagógicos, professores e pais dentro do ambiente escolar. Os temas abordados podem ser pesquisados com os alunos na web e divulgados nas redes sociais. Além disso, pode-se aproveitar os meios tecnológicos para anunciar e apresentar online o evento para aqueles que não estão participando dele.

Filmes: Pela sétima arte os alunos assimilam narrativas e podem relacioná-las a obras no papel. Além disso, os temas escolhidos, associados ao conteúdo pedagógico, auxiliam no aprendizado. Deixe a resenha do filme à disposição para os interessados nas redes sociais da biblioteca, aproveite também para promover uma enquete sobre o conteúdo da obra.

Concurso de Contos e Poesia: Um estímulo para que os estudantes desenvolvam o hábito de escrever e, consequentemente, o gosto pela leitura. Os concursos literários são verdadeiros celeiros de talentos e motivação para novos escritores. Após o resultado do concurso, exiba os textos ganhadores no blog da biblioteca.

Confrarias ${ }^{5}$ : 0 termo Confraria foi escolhido pela pesquisadora como forma de atrair os alunos para um encontro solene e rico em conhecimentos. O nome também é um atrativo maior para uma geração que conviveu intensamente com o bruxinho da série Harry Potter. São reuniões semanais de um grupo de estudantes que tenham interesses comuns. Os temas tratados surgem de acordo com a opinião dos próprios participantes. Como exemplo, podemos citar confrarias de música, informática, livros, etc. Professores e demais convidados são convidados à participar contribuindo com o dinamismo dos encontros. O objetivo desta atividade é construir o conhecimento de forma informal e prazerosa, aproximar alunos de diversas idades em torno de um tema comum, favorecendo a troca de ideias, fortalecendo a argumentação e a criatividade e estimular as buscas informacionais eficientes em ambientes digitais,

${ }^{5}$ Confraria da biblioteca: ambientes de reflexão sobre as Tecnologias de Informação e Comunicação e recuperação da informação. Resumo premiado no VI SEMINÁRIO DE EXTENSÃO DA UNESP DE MARÍLIA. 
Silvana Aparecida Borsetti Gregorio Vidotti; Lucirene Andréa Catini Lanzi; Edberto Ferneda. A mediação da informação aliada ao uso das tecnologias da informação e comunicação em uma biblioteca escolar

divulgando estas descobertas recentes nos próprios ambientes colaborativos, para fomentar uma rede de conhecimento e informação.

As TIC proporcionam um ambiente atraente à comunidade estudantil. No caso da Internet cria-se a condição de "navegar", descobrindo novos endereços ou localidades informativas, divulgando as descobertas e interagindo com outros colegas por meio de recursos tecnológicos disponibilizados no próprio ambiente das redes eletrônicas, o que gera impactos sobre os processos convencionais anteriores.

Certamente, estamos apenas no início de uma evolução que vai tornando o mundo cada vez mais digital e sem retorno ao modelo analógico. Nesse cenário de mutação tecnológica, a biblioteca escolar não se exime de sofrer os efeitos das mudanças.

A corresponsabilidade da biblioteca escolar em atuar para o aprimoramento de seu público não é ato altruístico a ser levado isoladamente, mas em cooperação com grupos existentes dentro da organização escolar. Trata-se de mais um desafio colocado à frente dos bibliotecários escolares para sua própria sobrevivência. Não podem mais ficar omissos ou indiferentes sobre sua inserção na ação pedagógica de capacitação dos estudantes. Essa inserção se inicia nos laboratórios de informática da escola, se houver, e se firma no uso, também da biblioteca.

Com o advento das TIC algo há muito tempo excluído do currículo escolar ganha agora maior realce: a própria vida do estudante. Por analogia, no caso da biblioteca escolar, insere-se agora um novo usuário, cada vez mais autônomo e adaptado às lides tecnológicas.

Para consolidar a ideia de que a biblioteca pode e deve ser um espaço dinâmico de ensino aprendizagem, fazendo, para isso o uso das TIC, como alicerce motivacional, será apresentado uma prática em uma escola particular na cidade de Marília - SP, chamada Colégio Cristo Rei.

\section{RESULTADOS E DISCUSSÃO}

O Colégio Cristo Rei é uma escola privada localizada em Marília/SP que atende mais de 1.500 alunos entre 2 e 18 anos. Com quase 60 anos de história. 0 
Silvana Aparecida Borsetti Gregorio Vidotti; Lucirene Andréa Catini Lanzi; Edberto Ferneda. A mediação da informação aliada ao uso das tecnologias da informação e comunicação em uma biblioteca escolar

Colégio possui uma biblioteca, a qual passou por diversas transformações nos últimos dois anos e pode servir como objeto de estudo para ilustrar a mediação da informação.

Antes da reformulação a biblioteca era um espaço pouco frequentado, considerado apenas para empréstimo de alguns livros interessantes para ler nas férias e finais de semana, encontrar amigos após as aulas, e fazer rapidamente alguns trabalhos e tarefas exigidos em sala de aula. A biblioteca também era utilizada como local para a realização de provas de recuperação e segunda chamada, ou seja, era associada a ocasiões de estresse.

Com este posicionamento pouco participativo e tradicional o local se distanciou dos seus usuários e não exercia plenamente seu papel. O bibliotecário não oferecia um ambiente propício, fosse por não possuir o material atualizado, por não estar a par do tema levantado em sala de aula, ou ainda por não usar as ferramentas adequadas e estimulantes para o aluno desenvolver uma boa busca informacional.

Para reverter esta situação procurou-se compor um ambiente jovial, adequado, esteticamente agradável. As paredes ganharam adesivos que transmitem mensagens de grandes pensadores e frases de motivação. Uma delas foi pintada com tinta especial onde os estudantes escrevem, fazem desenhos e deixam recados, expressando assim suas opiniões e impressões acerca do convívio escolar.

Além disso, diversas atividades foram planejadas para movimentar o fluxo de alunos e mostrar a eles que a biblioteca, assim como a obtenção do conhecimento, podem ser divertida e produtiva.

O local ganhou uma sala para contação de histórias decorada com temáticas infantis que remetem à imaginação e ao universo lúdico dos livros. Neste ambiente as crianças sentem-se à vontade e associam à leitura a algo prazeroso. Somado as ornamentações, foi desenvolvida uma dinâmica para os momentos de leitura onde a bibliotecária, em parceria com as professoras despertam nos alunos da Educação Infantil e Ensino Fundamental I a interpretação e o raciocínio sobre o assunto levantado na obra lida. Ou seja, durante a atividade conhecida como Hora do Conto as profissionais mediam a informação, fazendo com que as crianças absorvam a informação, mesmo que de forma inconsciente. 
Silvana Aparecida Borsetti Gregorio Vidotti; Lucirene Andréa Catini Lanzi; Edberto Ferneda. A mediação da informação aliada ao uso das tecnologias da informação e comunicação em uma biblioteca escolar

O Trocando uma Ideia é um dos momentos promovidos pela biblioteca do Colégio Cristo Rei para os alunos do Ensino Médio e Pré-Vestibular. A atividade consiste em reunir professores e alunos ao redor de temas polêmicos e atuais, onde pode-se expor pontos de vista e informações referentes ao assunto debatendo os prós e contras de cada questão levantada. Esta atividade aguça o pensamento crítico e favorece o desenvolvimento da consciência cidadã.

A exibição de filmes na sessão Cinema de Quinta também é uma das maneiras utilizadas pelo Colégio Cristo Rei para levar informações aos alunos. As obras cinematográficas são escolhidas de acordo com conteúdos que irão enriquecer a proposta da grade curricular.

$\mathrm{Na}$ maior parte dos dias letivos a biblioteca recebe exposições de obras de arte, fotos, elementos históricos, etc. Muitas exposições são acompanhadas pela visita de seus próprios artistas que explicam aos estudantes sobre os materiais expostos.

Uma das realizações com maiores proporções organizada pela Biblioteca do Colégio Cristo Rei é a Feira do Livro, realizada anualmente no mês de setembro. O evento nasceu com o objetivo de estimular a leitura e a cultura entre crianças e adultos da escola e da comunidade da cidade e toda a região. A feira reúne expositores e atrações artísticas e envolve milhares de pessoas, entre estudantes da rede pública e privada, universitários, profissionais e pais.

Com estas ações e utilização de uma linguagem visual, verbal e estrutural coerente com as expectativas de seus atendidos, a biblioteca consegue desempenhar sua função, atingindo as metas estabelecidas pela UNESCO para as bibliotecas escolares, conforme transcrevemos a seguir:

1. Apoio e realização dos objetivos do projeto educativo da escola e do currículo;

2. Inculcar e incutir nas crianças o hábito e o prazer da leitura, da aprendizagem e utilização das bibliotecas ao longo da vida;

3. Proporcionar oportunidades para experiências na criação e utilização de informações para adquirir conhecimento, compreensão, imaginação e prazer;

4. Apoiar todos os alunos para a aquisição de habilidades para avaliar e utilizar informações, independentemente do formato, meio ou meio de comunicação, tendo em conta a sensibilidade para as formas de comunicação que existem na comunicação; 
Silvana Aparecida Borsetti Gregorio Vidotti; Lucirene Andréa Catini Lanzi; Edberto Ferneda. A mediação da informação aliada ao uso das tecnologias da informação e comunicação em uma biblioteca escolar

5. Facilitar o acesso a recursos e oportunidades na economia local, regional, nacional e para que os alunos têm contato com as idéias, experiências e opiniões diferentes;

6. Organizar atividades que estimulem a consciência e a sensibilidade cultural e no social;

7. Trabalhar com alunos, professores, administração e famílias para o projeto educacional da escola, proclamando a idéia de que a liberdade intelectual e o acesso à informação são essências para a cidadania e participar de uma democracia com eficiência e responsabilidade;

8. Incentivar a leitura e promover os recursos e serviços da biblioteca escolar e fora de toda a comunidade escolar.

\section{CONSIDERAÇÕES FINAIS}

Não basta utilizar as TIC na biblioteca só pela modernidade ou variedade de aplicações. É necessário ter consciência da utilidade destes ou de qualquer outro meio de interesse dos alunos para poder mostrar sua qualidade e a utilidade prática.

O bibliotecário, antes de utilizar as TIC, deve fazer um levantamento profundo sobre as problemáticas com as quais esse instrumento de trabalho pode contribuir de forma relevante.

Por todas as razões anteriormente apontadas, o bibliotecário que queira utilizar as chamadas "novas tecnologias" na biblioteca como meio de aprendizagem e recursos informacionais deve adequar sua atitude aos novos requisitos pedagógicos, ou seja, como bibliotecário e colaborador do educador, consciente de sua nova responsabilidade, deve funcionar como elemento promotor do desenvolvimento pessoal do aluno, tornando-o uma pessoa crítica e ativa perante a sociedade, fomentando o desenvolvimento de uma consciência de cidadania.

Essa missão do bibliotecário só é possível se ele próprio admitir a sua necessidade de formação pessoal, bem como definir o seu espaço de intervenção. Tal como cada aluno que sente-se motivado a aprender a utilizar novos instrumentos, a experimentar "novos" caminhos, também o bibliotecário deve sentirse atraído por novos desafios e, acima de tudo, deve sentir-se seguro na sua "insegurança” pela novidade.

Daí, a necessidade de o bibliotecário ocasionar novas e diferentes atividades de aprendizagem que motivem o aluno e, sobretudo, que integrem conhecimentos extracurriculares, muitas vezes mais interessantes para os alunos e para as famílias. 
Silvana Aparecida Borsetti Gregorio Vidotti; Lucirene Andréa Catini Lanzi; Edberto Ferneda. A mediação da informação aliada ao uso das tecnologias da informação e comunicação em uma biblioteca escolar

Nesse sentido, é de primordial importância que os bibliotecários compreendam como é que os instrumentos tecnológicos (computadores, celulares, jogos eletrônicos, softwares, tablets, redes sociais etc.) podem ajudar a criar desafios pedagógico-didáticos, ou seja, mais do que conhecer por dentro o motor de um automóvel é preciso saber conduzi-lo muito bem.

A partir dessa realidade e como consequência de pesquisas realizadas sobre o tema é que surgiu a Confraria da Biblioteca, uma proposta pedagógica inovadora, baseada na realidade brasileira, que alia educação e tecnologia na formação do aprendiz, seja ele aluno regular de escolas públicas ou particulares, ou ainda usuários de centros de inclusão em comunidades menos favorecidas. O cerne desta proposta é reconhecer o fato de que o principal instrumento desse novo milênio não é o computador, e sim o próprio conhecimento, modelado pelas estratégias cognitivas que facilitam a tomada de decisão e a solução de problemas. É entender que a máquina é um meio, um instrumento que deve ser utilizado como recurso. A capacidade de identificar, para cada situação, a melhor solução, assim como a motivação que promove o interesse por aprender ao longo da vida, e a autoconfiança nas próprias habilidades, não virão das ferramentas e sim da capacidade dos mediadores do conhecimento de realizarem com sucesso suas tarefas.

\section{REFERÊNCIAS}

ALMEIDA JÚNIOR, Oswaldo Francisco de. Mediação da informação e múltiplas linguagens. In: ENCONTRO NACIONAL DE PESQUISA EM CIÊNCIA DA INFORMAÇÃO, 9., 2008, São Paulo. Anais... São Paulo, 2008. CD-ROM. p. 3.

CAMPELLO, Bernadete Santos. Perspectivas de letramento informacional no Brasil: práticas educativas de bibliotecários em escolas de ensino básico.Enc. Bibli: R. Eletr. Bibliotecon. Ci. Inf., ISSN 1518-2924, Florianópolis, v. 15, n. 29, p. 184-208, 2010.

COHEN, Laura. Manifesto de um bibliotecário 2.0. Disponível em: <http://liblogs.albany.edu/library20/2006/11/a_librarians_20_manifesto.html>. Acesso em 20.dez.2009.

FARIAS, Christianne Martins; VITORINO, Elizete Vieira. Competência informacional e dimensões da competência do bibliotecário no contexto escolar. Pespectivas em Ciência da Informação. v. 14, n. 2, Belo Horizonte, 2009. 
Silvana Aparecida Borsetti Gregorio Vidotti; Lucirene Andréa Catini Lanzi; Edberto Ferneda. A mediação da informação aliada ao uso das tecnologias da informação e comunicação em uma biblioteca escolar

FERREIRA, Luciano Almeida. Como uma escola ingressa no século XXI? Estudo de caso sobre o uso das tecnologias de informação e comunicação e da biblioteca. 97 folhas. Dissertação ( Mestrado em Educação) Universidade Católica de Brasília, Brasília, DF, 2009.

FREIRE, Paulo.A importância do ato de ler. São Paulo: Cortez, 1995.

KUHLTHAU, C.C. et. al. Como usar uma biblioteca na escola: um programa de atividades para o Ensino Fundamental. Belo Horizonte: Autêntica, 2006.

O papel da biblioteca escolar no processo de aprendizagem. In: VIANNA, M. M. et al. Seminário Biblioteca Escolar: espaço de ação pedagógica. Belo Horizonte: Escola de Ciência da Informação da UFMG, 1999. p. 9-14.

LANZI, Lucirene Andrea Catini. Apropriação das Tecnologias de Informação e Comunicação em Bibliotecas Escolares: em busca de um espaço dinâmico. 176 páginas. Dissertação (Mestrado em Ciência da Informação) - Faculdade de Filosofia e Ciências, Universidade Estadual Paulista, Marília. 2012.

; L. A. C.; FERNEDA, E.; VIDOTTI, S. A. B. G. Confraria da biblioteca: ambientes de reflexão sobre as tecnologias de informação e comunicação. Revista Ciência em Extensão v. 7 (2), p. 184-185, 2011.

;L. A. C.; FERNEDA, Edberto; VIDOTTI, Silvana A.B.G.. Leitura e as TIC: a hora do conto utilizando tablet. IV SECIN - SEMINÁRIO EM CIÊNCIA DA INFORMAÇÃO.4. 2011. Londrina. Anais...Lon:2011

MACEDO, Neusa D. et. al. Biblioteca Escolar Brasileira em debate: da memória profissional a um fórum virtual. São Paulo: Ed. SENAC São Paulo: Conselho Regional de Biblioteconomia - 8ª região, 2005.

MAROTO, Lucia Helena. Biblioteca escolar, eis a questão! Do espaço do castigo ao centro do fazer educativo.Belo Horizonte: Autêntica Editora, 2009.

MODESTO, Fernando. MACEDO, Neusa D. et. al. Biblioteca Escolar Brasileira em debate: da memória profissional a um fórum virtual. São Paulo: Ed. SENAC São Paulo: Conselho Regional de Biblioteconomia - 8 ${ }^{\mathrm{a}}$ região, 2005.

PALFREY, John.; GRASSER, Urs. Nascidos na era digital: entendendo a primeira geraçãode nativos digitais. Porto Alegre, 2011.

PARTRIDGE,H.;LEE,J.;MUNRO,C. Becoming "librarian 2.0": the skills, knowledge, and attributes required by Library and Information Science professionals in a web 2.0 word (and beyond). LIBRARY TRENDS, Universityof Illinois, Vol. 59, n. 1-2. P. 315-335. 2010. Disponível em:<www.highbean.com/doc/1P3-2238917661.html $>$.Acessado em: 12 dez de 2012.

SILVA, Armando Malheiro da; RIBEIRO, Fernanda. Recursos de informação: serviços e utilizadores. Lisboa: UniversidadeAberta, 2010. ISBN 978-972-674-672-0

UNESCO. Manifesto IFLA/UNESCO para Biblioteca Escolar. Disponível em:<http://archive.ifla.org/VII/s11/pubs/portuguese_brazil.pdf >. Acesso em: 05.fev.2011. 
Silvana Aparecida Borsetti Gregorio Vidotti; Lucirene Andréa Catini Lanzi; Edberto Ferneda. A mediação da informação aliada ao uso das tecnologias da informação e comunicação em uma biblioteca escolar

\section{Title}

Information access: research notes

\section{Abstract}

Introduction: This paper presents preliminary results of the research project "Information access: actions and strategies of the Chamber of Deputies to meet 12.527/2011 Law". Finally some considerations about the implementation of the Law within the Chamber of Deputies are presented.

Objectives: Discuss the matter of public information access after the new Brazilian information access law and his relationship between the theories information policy, information regime and informational state.

Methodology: Bibliographic research about several theoretical topics related to information access were raised, for example: the concept of information, information policy, informational state, information regime, electronic government and information asymmetry.

Results: The preliminaries data shows a convergence of information policies from many countries, for example, Finland, Canada and South Africa, to a same point, which indicates an increase of transparency and a bigger active disclosure of information public.

Conclusion: In Brazilian case, in the relationship between State and citizen, the new information access law means a materialization paradigm change or the concretization de other information regime. The sanction of this law can be interpreted as another step to increase the transparency and the affirmation of democratic relationship between State and society.

Key words: Information Access. Law 12.527/2011. Democratization of information

\section{Título}

Acceso a la información: notas de investigación

\section{Resumen}

Introducción: Presenta los resultados preliminares del proyecto de investigación "El acceso a la información: acciones y estrategias de la Cámara de Representantes para cumplir la Ley 12.527/2011". Presenta algunas consideraciones sobre la aplicación de la Ley de la Cámara de Diputados.

Objetivo: Discutir la cuestión del acceso a la información pública después de la promulgación de la nueva ley de acceso a la información a la luz de las teorías sobre la política de información, sistema de información y la información de estado.

Metodología: Investigación bibliográfica en la literatura sobre diversos temas teóricos relacionados con el acceso a la información, por ejemplo: el concepto de información, la política de información, el estado de información, sistema de información, el gobierno electrónico y la asimetría de la información.

Resultados: Los datos preliminares de este estudio apuntan a una convergencia de las políticas en varios países, como Finlandia, Canadá, Sudáfrica, en el mismo punto, lo que indica una mayor transparencia y una mayor difusión activa de la información pública. 
Silvana Aparecida Borsetti Gregorio Vidotti; Lucirene Andréa Catini Lanzi; Edberto Ferneda. A mediação da informação aliada ao uso das tecnologias da informação e comunicação em uma biblioteca escolar

Conclusión: En el contexto brasileño, la relación entre el Estado y los ciudadanos, la ley de acceso a la información significa la realización de un cambio de paradigma, o la realización de otra información del sistema. La sanción de esta norma legal se puede entender como un paso hacia la transparencia y la afirmación de las relaciones democráticas entre el Estado y la sociedad.

Palabras clave: Acceso a la información. Ley 12.527/2011. La democratización de la información.

Recebido em: 15.07.2014

Aceito em: 05.10.2014 